\title{
Factors Affecting Outcomes of Cardiopulmonary Resuscitation in a Nephro-Urology Unit: A Retrospective Analysis
}

\author{
Sadhvi Sharma ${ }^{1} \odot$, Padmalatha Raman $^{2} \odot$, Maneesh Sinha ${ }^{3}$, Alka S Deo $^{4} \odot$
}

\begin{abstract}
Background: Availability of cardiopulmonary resuscitation (CPR) data from India is limited in published literature and data on patients with renal disease even more so. Documented survival-to-discharge rates worldwide range from 8 to $15 \%$ in renal disease as compared to $25 \%$ in the general population.

Methods: An institution-wide format for collection of cardiac arrest data was introduced in late 2015 . We have analyzed all adult onsite cardiac arrests from January 2016 to December 2019. Patient characteristics and CPR parameters were both studied in detail. Primary endpoint was defined as survival to discharge. Association between patient and treatment characteristics and survival to discharge was studied.

Results: Successful CPR resulting in patient discharge occurred in 28 (31.4\%) out of 89 patients. A very strong association was found between mortality and prolonged CPR $(p<0.00001)$. Events occurring out of hours $(p=0.0029)$, patients admitted in the intensive care unit (ICU) ( $p=0.03)$, initiated on inotropes $(p=0.003)$, and patients already on a ventilator $(p=0.0018)$ had poorer outcomes. Sepsis as the etiology emerged as the most significant association with mortality $(p=0.0007)$. Patient characteristics such as age, sex, presence or absence of chronic kidney disease, type of dialysis treatment, and vintage were found to be insignificant.

Conclusion: Analysis revealed survival to discharge of 31.4\%. Sepsis in association with renal disease has been found to be consistent with higher risk for mortality. Other factors such as an out of hours event, admission to ICU, early intubation and inotrope initiation were associated with worse outcomes.
\end{abstract}

Keywords: Cardiopulmonary resuscitation, Causes of cardiac arrest, Renal insufficiency, Sepsis, Survival to discharge.

Indian Journal of Critical Care Medicine (2022): 10.5005/jp-journals-10071-24146

\section{HIGHLIGHTS}

In patients with renal disease, sepsis as an etiology for cardiac arrest has emerged as an important cause of death with poorer prognosis than cardiac disease which may be partially reversible. Worse survival was noted in sicker patients, and dialysis vintage did not make a difference to survival.

\section{INTRODUCTION}

Cardiopulmonary resuscitation (CPR) in the recent decades has seen a steady improvement in survival. International survival rates for CPR have shown a gradual increase over the decades: from $15 \%^{1}$ in 1992 to $24.8 \%$ in $2016 .^{2}$

The updated ACC/AHA guidelines of 2015 make recommendations for 17 special conditions, but renal failure does not find a mention. ${ }^{3}$ The European Resuscitation Council states a few specific guidelines on management of patients who have a cardiac arrest during hemodialysis but is silent on the management of cardiac arrest due to other causes. ${ }^{4}$ Patients with chronic kidney disease (CKD) are a high-risk group where cardiac arrests occur due to cardiovascular comorbidities. We conducted an observational study of all cardiac arrest events in our nephrology unit to assess the overall rate of return of spontaneous circulation (ROSC) and subsequent survival to discharge and the various factors affecting them. Patient parameters, CPR parameters, and the general trend of survival to discharge over the years were also studied.

\section{Materials and Methods}

The data was collected in our tertiary nephrology care unit, from January 2016 to December 2019, on a standardized format (Fig. 1).
1,2,4 Department of Anaesthesiology and Critical Care, NU Hospitals, Bengaluru, Karnataka, India

${ }^{3}$ Department of Urology, NU Hospitals, Bengaluru, Karnataka, India

Corresponding Author: Sadhvi Sharma, Department of Anaesthesiology and Critical Care, NU Hospitals, Bengaluru, Karnataka, India, Phone: +91 8939138561, e-mail: sadhvi.veevee@gmail.com

How to cite this article: Sharma S, Raman P, Sinha M, Deo AS. Factors Affecting Outcomes of Cardiopulmonary Resuscitation in a NephroUrology Unit: A Retrospective Analysis. Indian J Crit Care Med 2022;26(3):322-326.

Source of support: Nil

Conflict of interest: None

This study received a full approval from the Institutional Ethics Committee. Retrospective analysis of all events was done. Those patients in whom CPR was not attempted and those events which had incomplete data were excluded. Event due to poisoning, suicide, or homicide, patients aged less than 18 years, pregnant women, or patients with mental disabilities were excluded from the study.

The primary endpoint was survival to hospital discharge or transfer to another center. The secondary endpoint was achievement of ROSC. Discharge from hospital or transfer elsewhere was recorded as survival to discharge. Patient parameters and CPR parameters were both studied.

Patient characteristics studied were as follows: age, gender, diagnosis of diabetes mellitus (DM), systemic hypertension (HTN), CKD, type of dialysis treatment-hemodialysis (HD) or

(0) The Author(s). 2022 Open Access This article is distributed under the terms of the Creative Commons Attribution 4.0 International License (https://creativecommons. org/licenses/by-nc/4.0/), which permits unrestricted use, distribution, and non-commercial reproduction in any medium, provided you give appropriate credit to the original author(s) and the source, provide a link to the Creative Commons license, and indicate if changes were made. The Creative Commons Public Domain Dedication waiver (http://creativecommons.org/publicdomain/zero/1.0/) applies to the data made available in this article, unless otherwise stated. 


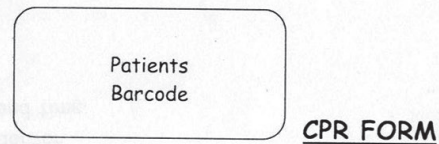

Version: 02

NUH-ICU-CL-O3

(encircle appropriate entries where applicable)

Date: ----/----/---- Code Blue announced at: ----/---- am/pm Location:

Witnessed/Not witnessed

Initial clinical assessment: Pulse - well felt/absent

Breathing: Spontaneous/agonal/apnea/ventilator

Compressions started at: -----/---- am/pm

CBG: $\quad \mathrm{mg} / \mathrm{dL}$

Monitor connected at: ----/---- $\mathrm{am} / \mathrm{pm}$

ECG tracing taken at: -----/---- $\mathrm{am} / \mathrm{pm}$

Initial cardiac rhythm

Bag valve mask breathing started at: ----/---- $\mathrm{am} / \mathrm{pm}$

IV access: present/absent

if ABSENT, cannula inserted at: ----/---- $\mathrm{am} / \mathrm{pm}$

Intubation: Done/not done

if done, tube - endotracheal/laryngeal mask

Time of intubation: -----/---- $\mathrm{am} / \mathrm{pm}$

Defibrillation for initial cardiac rhythm: Done/not done

if done, time of defibrillation: ----/---- am/pm Energy:------KJ

Return Of spontaneous circulation

Present

Time of ROSC: ----1---- $\mathrm{am} / \mathrm{pm}$

Rhythm following ROSC:

ECG diagnosis

Patient transfer

Cause of cardiopulmonary arrest

\section{Absent}

Time of death: -----1--- am/pm

Family notified by:

Cause of death:

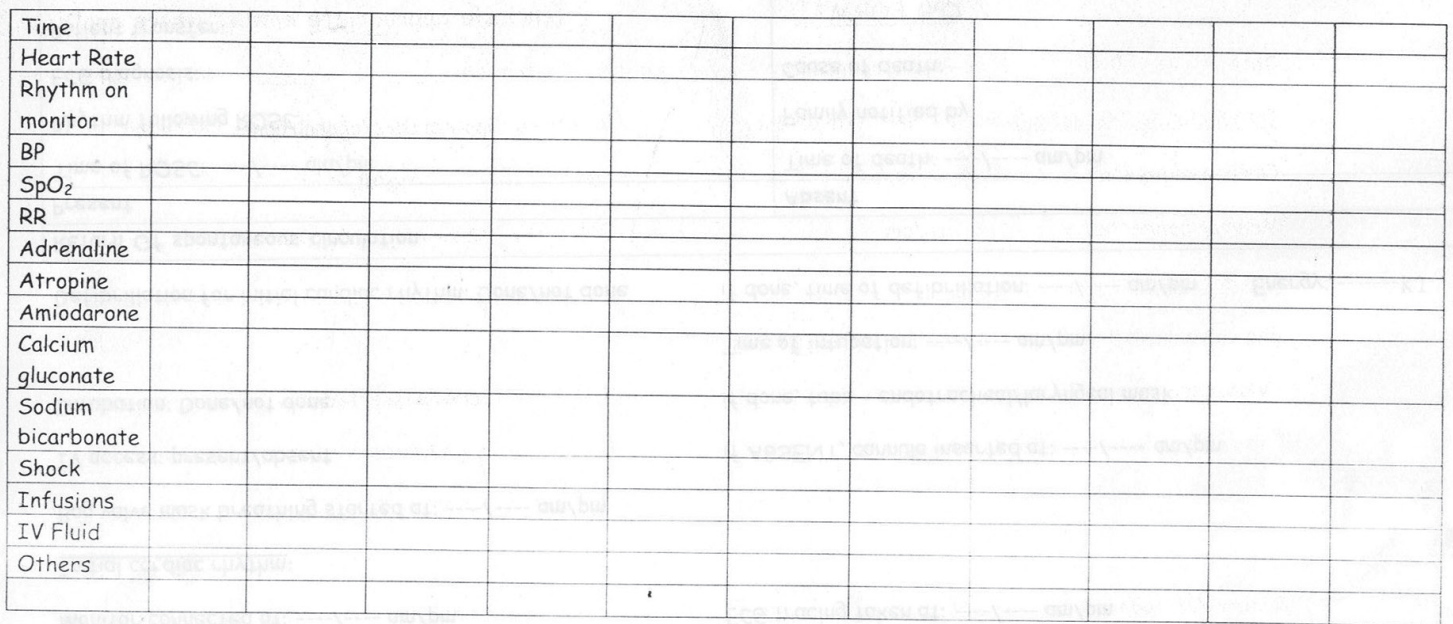

Events prior to CPR:

ECG:

Oxygen saturation: $\quad B P$ :

MEWS - Done/Not done

Diaznosis:

if done, maximum score within previous 6 hours

Supports:

Duty doctor:

Date and time:

Consultant:

Fig 1: CPR form 
peritoneal dialysis (PD) and dialysis vintage, cerebrovascular event, peripheral vascular disease (PVD), ischemic heart disease (IHD), decompensated liver disease, and associated malignancies. CPR parameters studied were as follows: location of cardiac arrest, whether the cardiac arrest was witnessed, ECG rhythm on presentation, whether the rhythm was shockable or not, whether intubation was done at the time of the event or already on a ventilator, cause of the cardiac arrest, time at which a code was announced, total duration of CPR, whether ROSC was achieved or not, the details of the inotropic supports, and survival to discharge. Patients with a glomerular filtration rate less than $60 \mathrm{~mL} / \mathrm{min} / 1.73 \mathrm{~m}^{2}$ as assessed by MDRD formula for more than 3 months were considered to be CKD. Dialysis vintage was divided into three categories: $<12$ weeks, 12-26 weeks, and $>26$ weeks. Total duration of CPR performed was divided into three groups: less than 15 minutes, 15-30 minutes, and more than 30 minutes. Out of hours event was described as any event occurring after $6 \mathrm{pm}$ and before 8 am on weekdays and any event occurring on a Sunday. Analysis of events according to days of the week and a trend of ROSC and survival to discharge over the years were studied.

Quality indicators of CPR such as compression rate, compression depth, hands off time, ventilation rate, leaning on the chest wall, end tidal carbon dioxide levels, diastolic blood pressure during the resuscitation could not be studied due to the retrospective nature of the study. Targeted temperature management in patients who achieved ROSC was not done because our institution is not equipped adequately.

Categorical data are presented as number (\%) and continuous data as mean \pm SD. Significance level was assessed at $5 \%$. Chi-square was used to find the significance on categorical scale between two or more groups. Fisher exact test was used when the sample size was small. Pearson's coefficient of correlation was used to determine association between number of comorbidities and survival.

\section{Results}

ROSC was achieved in $43.82 \%$ of events, and $30.85 \%$ of events had survival to discharge. A total of 100 events occurred in 89 patients over 4 years. Seventy-eight patients had one event each, and 11 patients had two events each. Six events were excluded from analysis due to incomplete data or CPR not attempted. Analysis was done for 94 events in 89 patients, of which 39 events had ROSC and 29 events resulted in survival to discharge.

Patients who were already on a ventilator at the time of the event when compared to patients who were intubated during the event had a poorer chance at $\operatorname{ROSC}(p=0.0022 ; \mathrm{OR}=5.35)$ and were less likely to survive to discharge $(p=0.001$; OR $=9.0)$. Duration of CPR correlated negatively with survival to discharge $(p<0.00001)$. Early defibrillation did not result in any improvement in survival to discharge or ROSC. Inotropic support was initiated for 20 events (out of 29) in the survivors' group, as compared to 42 (out of 69 ) in the non-survivors' group ( $p=0.0035$ ). Among all causes of cardiac arrest, cardiogenic and septicemic were the two most common causes. All cause analysis revealed that sepsis was the single most significant cause to adversely affect survival $(p=0.00236)$.

Patient characteristics such as age, sex, medical conditions such as DM, HTN, IHD, CVA, and PVD, diagnosis of CKD, patients on $\mathrm{HD} / \mathrm{PD}$, dialysis vintage, witnessed vs unwitnessed events, and defibrillation at the time of the event did not have any correlation with ROSC or survival to discharge. Events analyzed according to days of the week revealed no significant difference in incidence. The occurrence of events over the years has been fairly consistent with an average of 23 events per year (Fig. 2).

Out of 94 events, 3 had an out of hospital cardiac arrest (OHCA), and all the remaining events occurred in the hospital. There were 12 unwitnessed cardiac arrests (including three OHCAs); however, the presence of witness did not confer any survival advantage. Odds ratio for survival to discharge when analyzed according to location was ICU vs HD unit $(O R=8.75)>I C U$ vs $E R(O R=5.3)>I C U$ vs ward $(\mathrm{OR}=3.33)>\mathrm{ICU}$ vs OHCA $(\mathrm{OR}=2.91)$. Although a total of 53,322 sessions of dialysis were conducted over a period of 4 years, only five events occurred in the hemodialysis unit.

We had 11 events in 10 patients with chronic liver disease (CLD) (10 chronic, 1 acute fulminant) with CKD on HD of which there were 3 events of ROSC and no survivors. Total number of comorbid conditions each patient had was categorized from 0 to 6 and correlated with survival to discharge. Pearson's coefficient of correlation yielded $r=0.28(p=0.14)$.
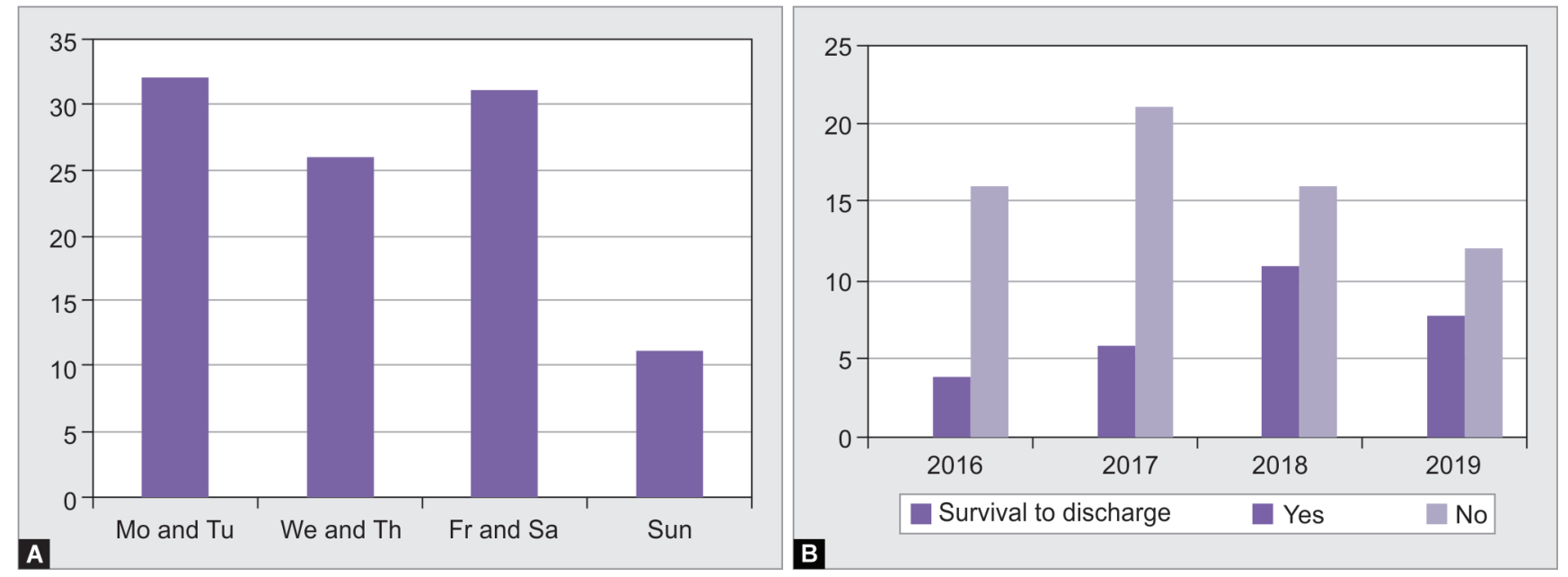

Figs $2 \mathrm{~A}$ and $\mathrm{B}$ : Event distribution according to timeline 


\section{Discussion}

Patients with renal dysfunction, who sustain cardiac arrest, have poor rates of survival to discharge; barely $8-15 \% .^{1,5-8}$ Some experts claim that CPR must be performed only for those patients who have a reasonable chance of survival, quoting that CPR is a time- and resource-consuming effort. ${ }^{7}$ The largest study from India done in the emergency room quotes a survival to hospital admission of $29.5 \%$ and survival to discharge of $9.9 \% .{ }^{9}$ Earlier North American studies quote a survival to discharge of $6-8 \%{ }^{1,10}$ With 5-year mortality after diagnosis of CKD hovering at $70 \%,{ }^{11}$ CPR was not even attempted in patients with underlying renal dysfunction. ' In our study, survival to discharge rate was $31.4 \%$. We have a designated CPR committee that oversees training, conducts mock drills, performs analysis of real cardiac arrest events, and identifies opportunities for improving response to a said event. All medical and nonmedical staff are routinely trained in basic life support (BLS) and encouraged to give CPR. Such training programs conducted routinely have been proven to improve hospital ROSC and survival to discharge rates. ${ }^{12}$

Sepsis was associated with a significantly lower chance of survival to discharge in contrast to all other causes of cardiac arrest $(\mathrm{OR}=6.3)(p=0.0007)$. This is in sharp contrast to other studies who quote cancer and cardiac etiology to be the leading cause of death in patients with renal dysfunction. ${ }^{13,14}$ For each $5 \mathrm{~mL} / \mathrm{min} / 1.73 \mathrm{~m}^{2}$ decrease in estimated glomerular filtration rate (GFR), there is an associated higher risk of death due to cardiovascular disease even in CKD patients who are not on HD. ${ }^{15}$ Some studies quote that there was no difference in survival to discharge in patients on HD and patients who were not on HD. ${ }^{1}$

We also found that patients who were likely to survive to discharge were almost always resuscitated within 15 minutes of the onset of the event $(p<0.00001)$. The average duration of CPR was 10.37 minutes in survivors vs 27.13 minutes in non-survivors. This is similar to outcomes worldwide, wherein patients who were resuscitated within 15 minutes had the highest chance of surviving to discharge. ${ }^{16}$ Patients who survive with a shorter CPR duration have a significantly better neurological outcome than those who survived with a longer CPR duration. ${ }^{17}$ Some authorities prescribe a longer duration of CPR. ${ }^{18}$ Early defibrillation at the time of the event did not produce any statistically significant difference in survival to discharge. Studies quote a survival rate as high as $41 \%$ for patients presenting with a shockable rhythm as their initial rhythm. ${ }^{6}$

We found that those who were already on a ventilator at the time of the event have a lower chance of survival than those who were intubated at the time of the event despite there being uninterrupted oxygenation ( $p=0.0018, \mathrm{OR}=9.0$ ). Inotrope initiation $(p=0.0035)$ and patients who were already in the ICU $(p=0.03)$ at the time of the event had a worse outcome as compared to patients who did not require inotropes or were elsewhere at the time of the event. Inotrope initiation was associated with higher mortality $(\mathrm{OR}=4.06)$. This is similar to other studies which found that ICU patients were less likely to survive an event. ${ }^{7}$ This goes to say that despite more aggressive management at the time of the event, these patients eventually did not survive to discharge. The best chance of survival is for ward patients who had been monitored prior to the event. ${ }^{6}$

Analysis of events according to day of the week revealed that there was no significant difference. We anticipated a higher number of events occurring on Monday/Tuesday as most patients have a longer interdialytic gap over the weekend, but this was not the case. ${ }^{13}$ Patients who presented with an event during regular working hours were more likely to be successfully resuscitated and survive to discharge $(p=0.004)$. Other authors also report lower successful resuscitation during out of hours CPRs. ${ }^{6,19}$ We had similar staffing round the clock and were unable to pinpoint the exact reason for this difference.

Our data do not reveal any differences in survival with respect to age or gender of the patients, presence or absence of CKD, HD or PD or dialysis vintage. Others have reported worse outcomes with increasing age ${ }^{6,7}$ and female gender. ${ }^{13} \mathrm{~A}$ total of 63 patients were on renal replacement therapy (59-HD, 4-PD). Studies reveal worsening survival with increasing dialysis vintage. ${ }^{5}$ We had 11 events in 10 patients with decompensated liver disease, none of whom survived. Several studies have identified CLD as a prognostic factor associated with worsened survival in patients who already have CKD. ${ }^{20-22}$ Some authors go as far as to question the utility of renal replacement therapy in patients with liver disease. ${ }^{22}$

\section{Limitations of Study}

As this was a single-center, time-bound study; the results could have been skewed due to inadequate numbers and institutional bias. Since most of our patients had renal disease, acidosis correction and potassium levels during the cardiac event are important parameters that need to be studied. Quality indicators of CPR were not studied. We could not follow-up the patients beyond survival to discharge. Quality of life postresuscitation including neurological outcome also merits analysis.

\section{Conclusion}

Sepsis as an etiology for a cardiac arrest event emerged as the single most important factor influencing mortality of CKD patients, along with longer CPR times.

\section{OrCID}

Sadhvi Sharma $\odot$ https://orcid.org/0000-0001-9984-0859

Padmalatha Raman (1) https://orcid.org/0000-0003-4351-9024

Maneesh Sinha ๑ https://orcid.org/0000-0002-7573-9219

Alka S Deo 니 https://orcid.org/0000-0002-6885-2686

\section{References}

1. Moss AH, Holley JL, Upton MB. Outcomes of cardiopulmonary resuscitation in dialysis patients. J Am Soc Nephrol 1992;3(6): 1238-1243. DOI: 10.1681/ASN.V361238.

2. El Asmar A, Dakessian A, Bachir R, El Sayed M. Out of hospital cardiac arrest outcomes: impact of weekdays vs weekends admission on survival to hospital discharge. Resuscitation 2019;143:29-34. DOI: 10.1016/j.resuscitation.2019.08.004.

3. Lavonas EJ, Drennan IR, Gabrielli A, Heffner AC, Hoyte CO, Orkin AM, et al. Part 10: special circumstances of resuscitation: 2015 American Heart Association guidelines update for cardiopulmonary resuscitation and emergency cardiovascular care. Circulation 2015;132(18_suppl_2):S501-S518. DOI: 10.1161/ CIR.0000000000000264.

4. Truhlář A, Deakin CD, Soar J, Khalifa GE, Alfonzo A, Bierens JJ, et al. European resuscitation council guidelines for resuscitation 2015: section 4. Cardiac arrest in special circumstances. Resuscitation 2015;95:148-201. DOI: 10.1016/j.resuscitation.2015.07.017.

5. Saeed F, Adil MM, Kaleem UM, Zafar TT, Khan AS, Holley JL, et al. Outcomes of in-hospital cardiopulmonary resuscitation in patients 
with CKD. Clin J Am Soc Nephrol 2016;11(10):1744-1751. DOI: 10.2215/ CJN.07530715.

6. Hirlekar G, Karlsson T, Aune S, Ravn-Fischer A, Albertsson P, Herlitz J, et al. Survival and neurological outcome in the elderly after in-hospital cardiac arrest. Resuscitation 2017;118:101-106. DOI: 10.1016/j.resuscitation.2017.07.013.

7. Schultz SC, Cullinane DC, Pasquale MD, Magnant C, Evans SR. Predicting in-hospital mortality during cardiopulmonary resuscitation. Resuscitation 1996;33(1):13-17. DOI: 10.1016/s03009572(96)00986-0.

8. Hirlekar G, Jonsson M, Karlsson T, Hollenberg J, Albertsson P, Herlitz J. Comorbidity and survival in out-of-hospital cardiac arrest. Resuscitation 2018;133:118-123. DOI: 10.1016/ j.resuscitation.2018.10.006.

9. Pandian GR, Thampi SM, Chakraborty N, Kattula D, Kundavaram PP. Profile and outcome of sudden cardiac arrests in the emergency department of a tertiary care hospital in South India. J Emerg Trauma Shock 2016;9(4):139. DOI: 10.4103/0974-2700.193348.

10. Sikaneta T, Aliazardeh B, Khosrodad N, Moody U, Mahdavi S. Cardiopulmonary resuscitation success rates in 402 patients with and without renal impairment at Canada's largest community hospital. J Nephrol Ther 2003;3:136. DOI: 10.4172/2161-0959.1000136.

11. Åhlström A, Tallgren $M$, Peltonen S, Räsänen P, Pettilä V. Survival and quality of life of patients requiring acute renal replacement therapy. Intensive Care Med 2005;31(9):1222-1228. DOI: 10.1007/s00134-0052681-6.

12. Sodhi K, Singla MK, Shrivastava A. Impact of advanced cardiac life support training program on the outcome of cardiopulmonary resuscitation in a tertiary care hospital. Indian J Crit Care Med 2011;15(4):209. DOI: 10.4103/0972-5229.92070.

13. Lafrance JP, Nolin L, Senécal L, Leblanc M. Predictors and outcome of cardiopulmonary resuscitation (CPR) calls in a large haemodialysis unit over a seven-year period. Nephrol Dial Transplant 2006;21(4):1006-1012. DOI: 10.1093/ndt/gfk007.
14. Thompson S, James M, Wiebe N, Hemmelgarn B, Manns B, KlarenbachS, et al. Cause of death in patients with reduced kidney function. J Am Soc Nephrol 2015;26(10):2504-2511. DOI: 10.1681/ASN.2014070714.

15. Navaneethan SD, Schold JD, Arrigain S, Jolly SE, Nally JV. Cause-specific deaths in non-dialysis-dependent CKD. J Am Soc Nephrol 2015;26(10):2512-2520. DOI: 10.1681/ASN.2014101034.

16. Cheema MA, Ullah W, Abdullah HM, Haq S, Ahmad A, Balaratna A. Duration of in-hospital cardiopulmonary resuscitation and its effect on survival. Indian Heart J 2019;71(4):314-319. DOI: 10.1016/ j.ihj.2019.09.002.

17. Welbourn C, Efstathiou N. How does the length of cardiopulmonary resuscitation affect brain damage in patients surviving cardiac arrest? A systematic review. Scand J Trauma Resusc Emerg Med 2018;26(1):77. DOI: 10.1186/s13049-018-0476-3.

18. Goldberger ZD, Chan PS, Berg RA, Kronick SL, Cooke CR, Lu M, et al.; American Heart Association Get With The Guidelines-Resuscitation (formerly the National Registry of Cardiopulmonary Resuscitation) Investigators. Duration of resuscitation efforts and survival after in-hospital cardiac arrest: an observational study. Lancet 2012;380(9852):1473-1481. DOI: 10.1016/S0140-6736(12)60862-9.

19. Peberdy MA, Ornato JP, Larkin GL, Braithwaite RS, Kashner TM, Carey SM, et al. Survival from in-hospital cardiac arrest during nights and weekends. Journal of the American Medical 2008;299(7):785-792. DOI: 10.1001/jama.299.7.785.

20. Kim AJ, Lim HJ, Ro H, Jung JY, Lee HH, Chung W, et al. Liver cirrhosis leads to poorer survival in patients with end-stage renal disease. Korean J Intern Med 2016;31(4):730. DOI: 10.3904/kjim.2014.328.

21. Chien CC, Wang JJ, Sun YM, Sun DP, Sheu MJ, Weng SF, et al. Long-term survival and predictors for mortality among dialysis patients in an endemic area for chronic liver disease: a national cohort study in Taiwan. BMC Nephrol 2012;13(1):43. DOI: 10.1186/1471-2369-13-43.

22. Howard CS, Teitelbaum I. Renal replacement therapy in patients with chronic liver disease. Semin Dialysis 2005;18:212-216. DOI: 10.1111/j.1525-139X.2005.18315.x. 